\title{
An investigation on the effects of business intelligence and enterprise resources planning on TQM
}

\author{
Mehrdad Nouri Koupaei ${ }^{\mathrm{a}}$ and Mohammad Mehdi Movahedi ${ }^{\mathrm{b}^{*}}$
}

${ }^{a}$ Department of Industrial Management, Islamic Azad University, Firoozkuh Branch, Iran ${ }^{b}$ Assistant Professor, Department of Industrial Management, Islamic Azad University, Firoozkuh Branch, Iran

\section{H R O N I C L E}

Article history:

Received December 10, 2013

Received in revised format

10 March 2013

Accepted April 42014

Available online

April 62014

Keywords:

Business Intelligence

Enterprise Resource Planning

Total Quality Management

Smart Management

\section{A B S T R A C T}

Nowadays Business Intelligence (BI) tools provide several decision support environment in enterprise systems like Enterprise Resource Planning (ERP) and they are mainly associated with computer-based techniques used in identifying, extracting and analyzing business data, such as sales revenue by products and/or departments, or by associated costs and incomes. The purpose of this paper is to provide a unified framework for the application of BI in ERP systems, which results in value-added quality control and management systems. In this paper, we expect to create business process automation and interaction between environment and technology by applying BI in ERP. Finally, a model is developed to represent the relationship between BI (as enabler of ERP) and the implementation of total quality management (TQM). The results indicate that using business intelligence, as an enabler of ERP, had good effect on achieving successful implementation of all three steps of Mukherjee model.

\section{Introduction}

Total quality management (TQM) is believed to be one of the primary sources on business development. Although TQM normally generates a sustainable competitive advantage, there is, surprisingly, little or no theory to confirm (Reed et al., 2000). In order to deal with the impacts of globalization, the pressure to bring out new products and services rapidly and to improve operations are considered as the most important priorities of business organizations in the future (Research, 2012). Enterprise resource planning (ERP) system, a set of highly integrated applications, which consists of applications modules, which can be applied to manage most of the business functions within an organization and it was introduced as an enabler for the implementation of effective TQM (Movahedi \& Nouri Koupaei, 2011; Li et al., 2008). However, management and ERP systems implementation have tended to concentrate on their transactional and record-keeping perspectives, rather than on their decision-support capabilities (Holsapple \& Sena, 2005). Nevertheless, most

* Corresponding author

E-mail addresses: mmmovahedi@gmail.com (M. M. Movahedi)

C) 2014 Growing Science Ltd. All rights reserved.

doi: $10.5267 /$ j.uscm.2014.4.001 
organizations still experience insufficient business intelligence (BI) in their decision-making processes when using ERP (Ghazanfari et al., 2011). Consequently, there have been various techniques introduced to evaluate and assess the intelligence-level of enterprise systems to improve decision support. This paper proposes BI tools as an intermediary for the ERP systems implementation on Improving Mukherjee's Model (Holistic Management System for world-class performance and leadership), and combines a comprehensive review of recent literature with statistical methods for factor analysis.

\section{Mukherjee's Theory}

Although there are many successful cases of TQM but TQM is not an all-embracing solution for eliminating all ills and meeting current challenges from globalization and liberalization. Therefore, Mukherjee (2006) presented a model for organization's world-class performance. This model has a three-step module including Foundation, Infrastructure and Total Quality Management and each consists of further three sub-divisions each, as follow,

Foundation: Customer focus, continuous improvement and strategic quality planning.

Infrastructure: Total organization involvement, logistics and supply chain management and quality management system

Total quality management: Quality planning, quality control and quality improvement.

This model is shown in the Fig. 1.

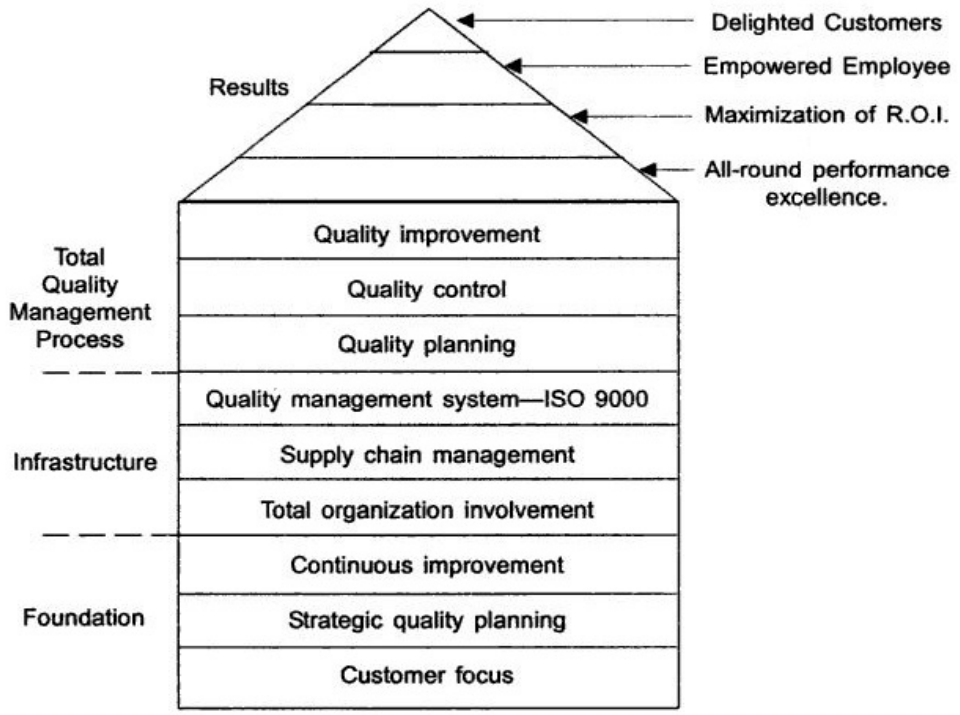

Fig.1. Mukherjee's theory of holistic management system for world-class performance \& leadership (Mukherjee, 2006)

According to Mukherjee's theory, if this model is implemented step by step, it will help the organization achieve its end objectives, i.e., its vision or the long term strategic position that the organization is aiming to achieve. The practicing of this model will ensure the organization to attain 'total quality' in every sphere of its working, i.e., to attain the ultimate in its performance, which is the best in its class in the world (Mukherjee, 2006). As regards ERP systems creates business process automation and interaction between environment and technology, and according to the benefits of ERP systems and the relationship between TQM and ERP systems, a model provided for applying ERP in effective implementation of TQM base of Mukherjee's theory (Movahedi et al., 2011) 


\begin{tabular}{|c|c|c|}
\hline \multirow{9}{*}{ ERP } & \multirow{3}{*}{$\begin{array}{c}\text { Total Quality } \\
\text { Management Process }\end{array}$} & Quality improvement \\
\hline & & Quality control \\
\hline & & Quality planning \\
\hline & \multirow{3}{*}{ Infrastructure } & Quality management system \\
\hline & & Supply chain management \\
\hline & & Total organization involvement \\
\hline & \multirow{3}{*}{ Foundation } & Continuous improvement \\
\hline & & Strategic quality planning \\
\hline & & Customer focus \\
\hline
\end{tabular}

Fig. 2. The effects of ERP systems on the three steps of Mukherjee' Model

The findings of the study indicated a conceptual model that show ERP systems can use as an enabler for the implementation of effective TQM until the three-step are improved to global level.

Today, BI has plays essential role on the creation of the current information for operational and strategic business decision-making (Popovič et al., 2010) and to survive in the harsh environment, high-level management needs business intelligent information to efficiently manage corporate operations and support their making of decisions (Cheng et al., 2009).

This paper investigates the role of advantages of $\mathrm{BI}$ as a mediator for the implementation of ERP systems on Improving Mukherjee's Model. The findings of this paper will explain how the combination of BI and ERP systems can be used as an enabler for the implementation of effective TQM until the three-step are improved to its final stage. So the theoretical model in this study is shown below:

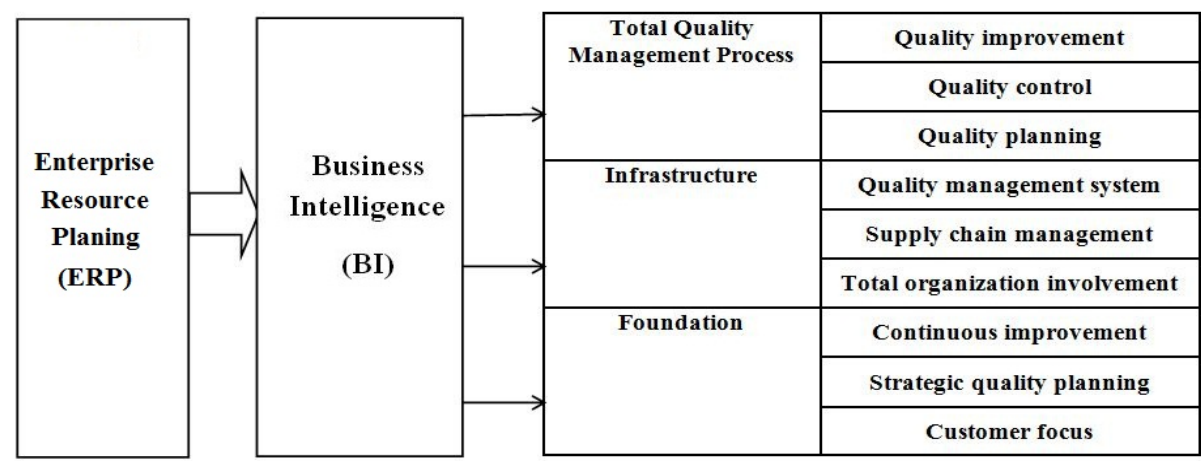

Fig. 3.The combination of BI and ERP Systems as an enabler on the three steps of Mukherjee' Model

BI tools can play a major role in increasing the quality of decisions. Sometimes these smart business decisions are associated with immediate response and it is often used to reduce the time and facilitates decisions. But in all cases, the use of BI is to be proactive (Negash, 2004). By combining enterprise systems as well as BI, enterprise-wide data can be collected and analysed and decisionmaking process can be facilitated. BI tools can analyse the business scenarios in long and short term by using existing data in enterprise information systems. In addition, it can add some features such as prediction of the required information and indicators to ERP's modules. Several quality indicators exist for prediction of the ability of process and machine capability, which can prevent future errors in the system and product. BI can help organizations predict these quality indicators for the future. Thus, this paper investigates the using a combination of BI and ERP systems based on Mukherjee's theory. Therefore, suggested model can improve these three-step for global level. 
The purpose of this research is to investigate the effect of BI implementation as an enabler of ERP to improve TQM base on Mukherjee's theory. Many recent studies have focused on the application of ERP systems in TQM. Despite the differences between these researches, almost all of these researches provide a model for relationship between ERP and TQM. In some research provided a model for the relationship of TQM and ERP (Dudek-Burlikowska \& Szewieczek, 2008; Ifinedo \& Nahar, 2006; Jha \& Joshi, 2007; Kramer, 2008; Li et al, 2006; Sebastianelli \& Rishel, 2005; ShaoShao et al., 2006). Some studies examined the application of quality management in ERP systems (Kumar et al., 2009; Laframboise \& Reyes, 2005; Li, 2006. Madu \& Madu, 2003; Schniederjans \& Kim, 2003; Bosilj-Vukšić \& Spremić, 2005). In other study, the effects of ERP systems to achieve Six Sigma was investigated (Surendra, 2008; Varzandeh \& Farahbod, 2010). On the other hands, BI can be used to utilize the decision process of ERP. These techniques can increase sensitiveness, flexibility and accuracy of information management systems. The hybrid systems that contain two or more intelligence techniques have also been investigated (Kahraman et al., 2011). These systems leverage the large data infrastructure investments (e.g. ERP systems) made by firms, and have the potential to realise the substantial value locked up in a firm's data resources (Elbashir et al., 2008; Azma \& Mostafapour, 2012). Finally, BI systems are often implemented as enhancements to widely adopted ERP systems (Elbashira et al., 2008; Elbashir et al., 2010). Also custom BI solutions merge ERP data with other transactional data outside of the ERP solution, allowing executives to analyse data from multiple sources. Although these studies review different dimensions of ERP systems, but none of these studies has reviewed the effect of BI as an enabler of ERP in organizations to reach global level. According to Sullivan (1996) BI is a key enabler of TQM. This paper produces a framework for applying BI as an enabler of ERP in effective implementation of TQM in three-steps of Mukherjee theory. The scientific basis of this research is very strong and developed based on Mukherjee Studies.

\section{The proposed study}

\subsection{Hypothesis of research}

According to the proposed model of this research, the research hypotheses are refined after the literature review and baseline study and they are summarized as follows,

1. Hypothesis $\mathrm{H}_{1}$. Using Business Intelligence (BI) in ERP systems influences on implementation TQM Process.

2. Hypothesis $\mathrm{H}_{2}$. Using Business Intelligence (BI) in ERP systems influences on implementation TQM Infrastructure.

3. Hypothesis $\mathrm{H}_{3}$. Using Business Intelligence (BI) in ERP systems influences on implementation TQM foundation.

These three hypotheses are shown in the following proposed model:

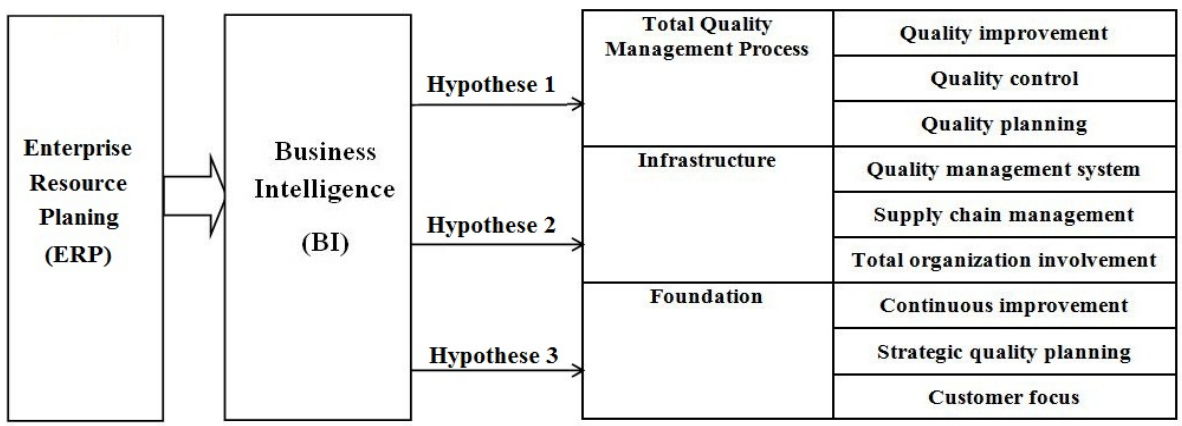

Fig. 4. The conceptual model: The impacts of BI (in ERP systems) on the three steps of Mukherjee' Model 
Statistical community of this study were including the experts in the field quality management and ERP systems such as: Quality control managers in organizations that have been implemented ERP, book authors, researchers, professors and masters and university faculty members, who have expertise in this area.

The first hypothesis consists of three parts: Quality planning, Quality control and Quality improvement. To test this hypothesis, 17 questions, in the questionnaire, are provided in which 6 questions are related to the first part, 6 questions related to the second part and 5 questions related to the third part.

The second hypothesis also consists of three parts: Organization involvement, Supply chain management and Quality management system. To test this hypothesis, 16 questions, in the questionnaire, are provided where 5 questions are related to the first part, 6 questions related to the second part and 5 questions related to the third part.

Finally, the third hypothesis also consists of three parts: Customer focus, Strategic quality planning and Continuous improvement. To test this hypothesis, 17 questions, in the questionnaire, are provided in which 5 questions are related to the first part, 7 questions related to the second part and 5 questions related to the third part. To obtain a high degree of validity and reliability of this paper, different measures have been undertaken. We use of multiple sources of information and opinions of experts and professors. Questions extracted for the questionnaire are based on the Mukherjee's theory and largely are related with research topic. We use the Cronbach's Alpha to calculate the reliability. The value of this factor has calculated 89.7 percent. The results indicate a high correlation between the results of questionnaire survey. The sample size formulas and procedures used for categorical data are very similar, but some variations do exist. We use the Morgan table to obtain the sample size (Krejcie $\&$ Morgan, 1970). Since the data are qualitative and the number of statistical community is unlimited, the sample size is equal to 385 . After confirming the validity and reliability, the research questions were launched with online questionnaires and they were sent to statistical community. The results of these questionnaires were available for analysis, including number of samples, age and education of respondents. When the number of sample reached to 385 cases, the data were entered in SPSS and different hypotheses were tested.

\section{The results}

Questionnaires were distributed among experts, quality managers, book authors, researchers, professors, graduate students and university faculty members. Fig 5 shows personal characteristics of the participants who attended in our survey.

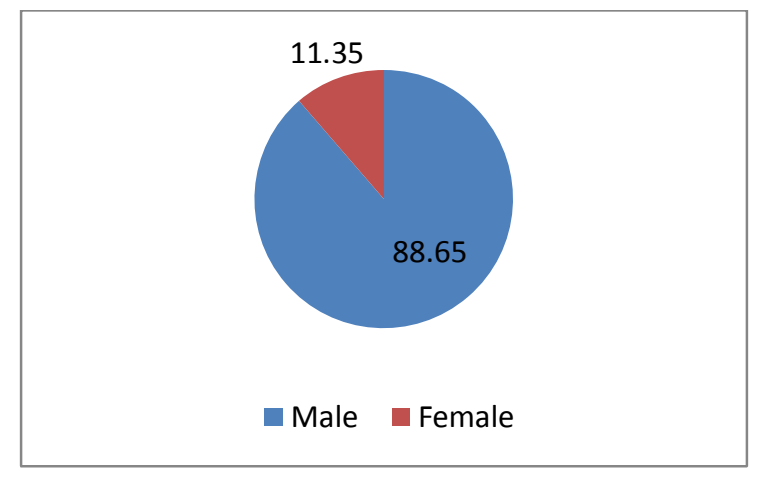

Gender

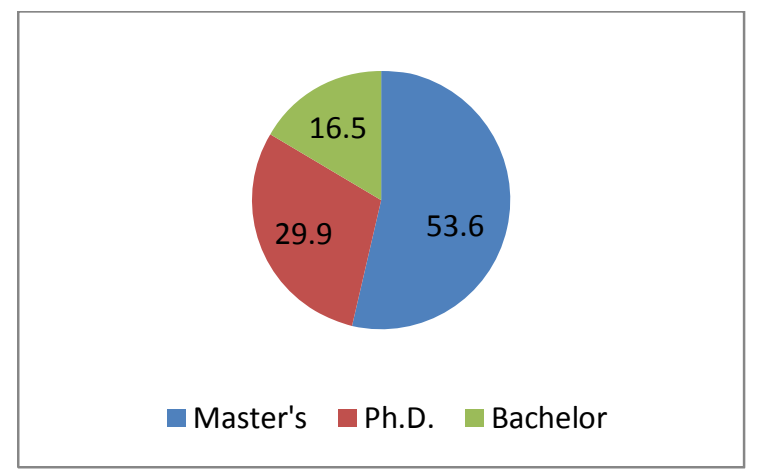

Educational background

Fig. 5. Personal characteristics of the participants 
According to the results of Fig. 5, 53.6\% of the participants maintained a master's degree, $29.9 \%$ had $\mathrm{Ph} . \mathrm{D}$. degrees and $16.5 \%$ held a bachelor's degree. In addition, most participants were male and only $11.35 \%$ of them were female. Finally, academic field of these experts was Industrial Engineering, Computer Engineering, IT, Management and few experts were graduated from the other academic fields. Results of the descriptive tests indicate that using business intelligence, as an enabler of ERP, had good effect on achieving successful implementation of all three steps of Mukherjee model. Therefore, a combination of BI and ERP Systems can be effective on organization's world-class performance. We used SPSS 19.0 to analyze the data. In following the results of examining hypotheses are offered:

\subsection{Testing Hypothesis 1}

$\mu \geq 0.5$ Using Business Intelligence (BI) in ERP systems impact on implementation Total quality management Process.

$\mu<0.5$, Otherwise.

The results of SPSS are presented in Table 1 and Table 2 as follows,

Table 1

One-Sample Statistics

\begin{tabular}{ccccc}
\hline & N & Mean & Std. Deviation & Std. Error Mean \\
\hline Hypothesis 1 & 385 & 0.64930 & 0.22529 & 0.02287 \\
\hline
\end{tabular}

\section{Table 2}

One-Sample Test

\begin{tabular}{ccccccc}
\hline & \multicolumn{6}{c}{ Test Value $=0.5$} \\
\cline { 2 - 7 } & \multirow{2}{*}{$\mathrm{t}$} & Df & Sig. (2-tailed) & Mean Difference & $\begin{array}{c}95 \% \text { Confidence Interval of the Difference } \\
\text { Lower }\end{array}$ & Upper \\
\cline { 2 - 7 } Hypothesis 1 & 6.526 & 96 & 0.000 & 0.14928 & 0.1039 & 0.1947 \\
\hline
\end{tabular}

\subsection{Testing Hypothesis 2}

$\mu \geq 0.5$ Using Business Intelligence (BI) in ERP systems impact on implementation Total quality management Infrastructure.

$\mu<0.5$ Otherwise.

The results of testing the second hypothesis are presented in Table 3 and Table 4 as follows,

Table 3

One-Sample Statistics

\begin{tabular}{ccccc}
\hline & $\mathrm{N}$ & Mean & Std. Deviation & Std. Error Mean \\
\hline Hypothesis2 & 385 & 0.6022 & 0.23532 & 0.02389 \\
\hline
\end{tabular}

\section{Table 4}

One-Sample Test

\begin{tabular}{ccccccc}
\hline & \multicolumn{8}{c}{ Test Value $=0.5$} \\
\cline { 2 - 7 } & \multirow{2}{*}{$\mathrm{T}$} & df & Sig. (2-tailed) & $\begin{array}{c}\text { Mean } \\
\text { Difference }\end{array}$ & $\begin{array}{c}\text { 95\% Confidence Interval of the Difference } \\
\text { Lower }\end{array}$ & Upper \\
\hline Hypothesis2 & 4.276 & 97 & 0.000 & 0.10216 & 0.0547 & 0.1496 \\
\hline
\end{tabular}




\subsection{Testing Hypothesis 3}

$\mu \geq 0.5$ Using Business Intelligence (BI) in ERP systems impact on implementation Total quality management foundation.

$\mu<0.5$ Otherwise.

The results of SPSS are given in Table 5 and Table 6 as follows,

Table 5

One-Sample Statistics

\begin{tabular}{ccccc}
\hline & $\mathrm{N}$ & Mean & Std. Deviation & Std. Error Mean \\
\hline Hypothesis3 & 385 & 0.7242 & 0.31351 & 0.03183 \\
\hline
\end{tabular}

Table 6

One-Sample Test

\begin{tabular}{ccccccc}
\hline & \multicolumn{6}{c}{ Test Value $=0.5$} \\
\cline { 2 - 7 } & $\mathrm{t}$ & df & Sig. (2-tailed) & Mean Difference & \multicolumn{2}{c}{ 95\% Confidence Interval of the Difference } \\
\cline { 3 - 7 } & 7.044 & 96 & 0.000 & 0.22423 & Lower & Upper \\
\hline Hypothesis 3 & 7.0410 & 0.2874 \\
\hline
\end{tabular}

\section{Conclusion}

In this paper, we have evaluated the impacts of BI in ERP systems based on Mukherjee' three step model. The results have indicated that applying BI, as an enabler of ERP, will influence on implementation of three-steps of Mukherjee theory. Note that this study was descriptive-cognition so statistical community of this study included the experts in the field quality management and ERP systems and researchers were unable to test the hypothesis as a case study in different organizations, separately. Therefore, this is the limitation of this research and we suggest to interested researchers to apply Mukherjee's model for various case studies in different organizations, separately.

\section{References}

Azma, F., \& Mostafapour, M. A. (2012). Business intelligence as a key strategy for development organizations. Procedia Technology, 1, 102-106.

Bosilj-Vukšić, V., \& Spremić, M. (2005). ERP System Implementation and Business Process Change: Case study of a pharmaceutical company. CIT. Journal of computing and information technology, 13(1), 11-24.

Dudek-Burlikowska, M., \& Szewieczek, D. (2008). The modern quality control of preproduction sphere in a company. Journal of Achievements in Materials and Manufacturing Engineering, 30(1), 79-86.

Cheng, H., Lu, Y. C., \& Sheu, C. (2009). An ontology-based business intelligence application in a financial knowledge management system. Expert Systems with Applications, 36(2), 3614-3622.

Elbashir, M., \& Williams, S. (2007). BI impact: The assimilation of business intelligence into core business processes. Business Intelligence Journal, 12(4), 45.

Elbashir, M. Z., Collier, P. A., \& Davern, M. J. (2008). Measuring the effects of business intelligence systems: The relationship between business process and organizational performance. International Journal of Accounting Information Systems, 9(3), 135-153.

Ghazanfari, M., Jafari, M., \& Rouhani, S. (2011). A tool to evaluate the business intelligence of enterprise systems. Scientia Iranica, 18(6), 1579-1590. 
Holsapple, C. W., \& Sena, M. P. (2005). ERP plans and decision-support benefits. Decision Support Systems, 38(4), 575-590.

Ifinedo, P., \& Nahar, N. (2006). Quality, impact and success of ERP systems: a study involving some firms in the Nordic-Baltic region. Journal of Information Technology Impact, 6(1), 19-46.

Jha, V.S, \& Joshi, H. (2007). Relevance of Total Quality Management (TQM) or Business Excellence Strategy Implementation for Enterprise Resource Planning (ERP) $-A$ Conceptual Study, $12^{\text {th }}$ International Conference on Information Quality (ICIQ-2007) at MIT, Cambridge, Massachusetts, USA, Nov 9-11, Published in triple blind peer- reviewed conference proceedings, pp. $347-362$.

Krejcie, R. V., \& Morgan, D. W. (1970). Determining sample size for research activities. Educational and psychological measurement, 30(3), 607-610.

Kramer, C. (2008). Quality Management for ERP Implementations, Master Thesis, Industrial Engineering and Management, University of Groningen.

Kahraman, C., Kaya, I., \& Çevikcan, E. (2011). Intelligence decision systems in enterprise information management. Journal of Enterprise Information Management, 24(4), 360-379.

Kumar, M.N., Suresh, A.V., \& Prashanth, P. (2009). Analyzing the quality issues in ERP implementation: A case study. Second International Conference on Emerging Trends in Engineering and Technology, ICETET-09, 759-764.

Laframboise, K., \& Reyes, F. (2005). Gaining competitive advantage from integrating enterprise resource planning and total quality management. Journal of Supply Chain Management, 41(3), 4964.

Li, L., Markowski, C., Xu, L., \& Markowski, E. (2008). TQM-A predecessor of ERP implementation. International Journal of Production Economics, 115(2), 569-580.

Li, Y. (2006). Research and implement of quality management system in ERP, intelligent strategies in product design, manufacturing, and management (IFIP). International Federation for Information Processing, 207, 570-575.

Madu, C. N., \& Madu, A. A. (2003). E-quality in an integrated enterprise. The TQM Magazine, 15(3), 127-136.

Movahedi, M. M., \& Nouri Koupaei, M. (2011). A framework for applying ERP in effective implementation of TQM. Middle-East Journal of Scientific Research,10(4), 489-495.

Mukherjee, P.N. (2006). Total Quality Management. Prentice Hall of India, New Delhi.

Negash, S. (2004). Business Intelligence. Communications of the Association for Information Systems, 13, 177-195.

Popovič, A., Turk, T., \& Jaklič, J. (2010). Conceptual model of business value of business intelligence systems. Management: Journal of Contemporary Management Issues, 15(1), 5-30.

Reed, R., Lemak, D. J., \& Mero, N. P. (2000). Total quality management and sustainable competitive advantage. Journal of quality management, 5(1), 5-26.

Research. G., (2012). Reimagining it: A survey of CIO. Gartner Research. http://www.gartner.com. downloaded on 19 September 2012.

Shaoshao, X. Y., Wu, J., Deng, C., Li, P. G., \& Jack Feng, C. X. (2006). A web-enabled collaborative quality management system. Journal of Manufacturing Systems, 25(2), 95-107.

Schniederjans, M. J., \& Kim, G. C. (2003). Implementing enterprise resource planning systems with total quality control and business process reengineering: survey results. International Journal of Operations \& Production Management, 23(4), 418-429.

Sebastianelli, R., \& Rishel, T. D. (2005). Integrating sap R/3 applications into a total quality management course. Academy of Information and Management Sciences Journal, 8(1), 59-69.

Sullivan, M. (1996). Business intelligence as a key enabler of total quality management. Competitive Intelligence Review, 7(1), 9-16.

Surendra, S.P. (2008). Manufacturing execution systems integrated with ERP \& SIX SIGMA for process improvements. Wichita State University.

Varzandeh, J., \& Farahbod, K. (2010). Comparative and Strategic Role of ERP in "Six Sigma" Quality. ASBBS Annual Conference: Las Vegas, 17(1), 511-516. 